\title{
Sons latino-americanos no século XX
}

Igor Lemos Moreira ${ }^{1}$

Resenha de: GONZÁLEZ, Juan Pablo. Pensando a música a partir da América Latina: problemas e questões. São Paulo: Letra e Voz, 2016, 268 p.

\section{Resenha recebida em: 18/12/2017}

Resenha aprovada em: 09/04/2018

Pensando a música a partir da América Latina: problemas e questões, lançado em 2016 pela editora Letra e Voz, é a primeira obra de Juan Pablo González publicada no Brasil. Musicólogo e historiador chileno, o autor pretende discutir a história da música e da musicologia latino-americanas no século $\mathrm{XX}$, visando entender os processos que levam à formação de ritmos, gêneros, artistas, identificações e diferentes representações no continente. Tendo em vista a extensão do recorte temporal e espacial, o autor toma como foco principal de análise três países - Chile, Argentina e Brasil, porém durante sua narrativa são estabelecidas conexões com outras regiões, tais como os Estados Unidos da América.

Composto por 12 capítulos, que podem ser divididos em dois grupos, o livro reúne textos produzidos e publicados pelo autor no decorrer de sua carreira como pesquisador, possibilitando ao seu leitor conhecer pontos distintos sobre a música latino-americana no século XX. Entre os principais temas abordados estão: as predominantes correntes historiográficas sobre a música latino-americana, as propostas pós-coloniais para compreensão da musicologia no século $\mathrm{XX}$, o espaço feminino na música, os movimentos de vanguardas e as relações inter-americanas.

Destacando a necessidade de abordagens multidisciplinares para os estudos sobre música, González estabelece nos seis primeiros capítulos diálogos com outras áreas de conhecimento, como os Estudos Culturais e Pós-coloniais. As articulações permitem ao autor abordar não apenas a música enquanto letra ou ritmo separadamente, mas destacar aspectos como oralidade, midialidade e performance. Sua proposta de

\footnotetext{
${ }^{1}$ Mestrando no Programa de Pós-Graduação em História da Universidade do Estado de Santa Catarina (UDESC), Brasil. Bolsista CAPES-DS e Integrante do Laboratório de Imagem e Som. E-mail: igorlemoreira@gmail.com
}

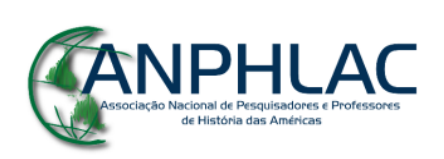

Revista Eletrônica da ANPHLAC, ISSN 1679-1061, №. 25, p. 327-331, Jul./Dez., 2018.

http://revista.anphlac.org.br 
trabalho destaca um elemento central das discussões mais recentes da historiografia musical - a capacidade da canção de presentificar passados e os significar. Deste modo, partindo das considerações do pesquisador chileno, podemos pensar que o estudo da música latino-americana no século XX aponta não apenas para processos criativos e artísticos, mas também para composições políticas, disputas de memória e de amplas temporalidades que se fazem presentes em momentos distintos de nossa contemporaneidade.

Os três primeiros capítulos discutem a formação de correntes de pensamento sobre a musicologia na América Latina no decorrer do século XX e XXI. Pensando primeiramente nas propostas americanistas, cujo objetivo era agregar partes das nações latino-americanas, interamericanas, projeto que partiria dos Estados Unidos, e dos Estudos latino-americanos, a partir do anos de 1980. Nesse contexto, o autor destaca que tais propostas não apenas não se encerraram, mas possuem permanências diretas em nosso presente, relembrando figuras que permanecem na cultura contemporânea, como Xavier Cugat e Carmen Miranda. Com a emergência da multidisciplinaridade na década de 1970 e 1980, os estudos na área passaram a incorporar novas problemáticas e discussões, como os pensamentos pós-coloniais e, mais recentemente, as humanidades digitais. A principal tese seria que, com o avançar das décadas, os pesquisadores na área de musicologia, e história da música, passaram a interpretar que a abordagem multidisciplinar seria fundamental para compreensão da música e da canção em suas mais distintas características e interlocuções. Os estudos em Ciências Humanas e Sociais na compreensão da canção nas construções sociais e humanas poderiam ser pensados como exemplos disso, a partir de categorias de identificações, gênero, etnia e classe.

Os capítulos IV e V são dedicados especialmente a debates sobre as produções historiográficas relativas a história da música latino-americana, a partir de documentos diversos produzidos nos encontros da IASPM na América Latina. Partindo disso, o autor pensa a organização desses eventos e seus anais como um balanço de pesquisas na área. Criada em 1980 a IASPM, a qual o autor foi diretor, aos poucos passou a abarcar e fomentar as discussões não apenas de gêneros musicais, mas também o estudo sobre pontos de escutas, redes de circulação e a própria indústria cultural. Tendo em vista que um dos focos recentes de estudo na música popular seriam os processos sociais de

\section{GANPHLAC}


significação em conjunto aos mecanismos de circulação e produção, González aponta para uma dificuldade recente de tais produções na área - os estudos sobre o consumo. Pontuando os avançados e embates do campo, o autor destaca que o estudo de música popular se faz extremamente pertinente, a partir dos anos de 1980, ao auxiliar a compreensão de tradições e visões de mundo em algumas comunidades que sempre foram marginalizadas.

Neste sentido, a canção é tomada como um processo que incorpora suas alterações ao longo de seu tempo, mediadas por performances, covers, apresentações e edições. A música não seria, nem deveria ser, compreendida como um objeto estático, mas sim fruto de um encadeamento constante de ressignificações por interprete e ouvinte/observador, tornando-se uma temática fundamental aos estudos da cultura contemporânea. Sendo uma das características de nosso regime de historicidade presentista (HARTOG, 2013), a resignificação continua de um passado em meio ao uma sensação de presente hipertrofiado e um futuro cujo o horizonte de expectativas se amplia constantemente é, em vários casos, aterrorizador. Sendo assim, os estudos sobre música latino-americana, partindo das considerações de González, seriam um objeto de estudo na compreensão de novas relações entre as dimensões passado/presente/futuro.

A partir do capítulo VII, são elencados estudos de caso e discussões a respeito de movimentos, figuras e construções rítmicas. No capítulo em questão, o autor analisa o espaço das mulheres na produção musical, partindo especialmente dos estudos feministas incorporados à musicologia latino-americana em 1990. A preocupação de González seria refletir sobre a construção musical do feminino e as estratégias discursivas de mulheres musicistas para romper barreiras, partindo do caso chileno, em quatro "perfis" diferentes: a cantora, a cantadora, a cantautora e a estrela da canção. Destacando o aumento da atividade pública de diversão, juntamente à expansão das rádios e dos discos, destaca-se que a figura feminina ocupou espaços distintos na música, como na década de 1920 e 1930 sendo estrelas em gêneros populares e folclóricos, ou na década de 1950, quando a figura masculina é reforçada em meio a um discurso misógino afirmando uma falta de profissionalismo entre as mulheres.

A discussão sobre o lugar feminino e as relações de gênero abre espaço para o autor debater, nos capítulos seguintes, as relações entre movimentos sociais, cultura política e os movimentos de vanguarda. Um dos principais exemplos levantados por

\section{CANPHLAC}

Revista Eletrônica da ANPHLAC, ISSN 1679-1061, №. 25, p. 327-331, Jul./Dez., 2018.

http://revista.anphlac.org.br 
González seriam os movimentos de "Vanguarda Primitiva" e de emergência do Rock n' Roll no Chile nas décadas de 1960 e 1970, analisados no capítulo IX. De acordo com o autor, a expansão do rock e dos movimentos hippies contribuiriam para a formação de novos artistas que buscaram "recuperar" identidades e heranças dos grupos indígenas pré-colombianos a partir experimentações e da música popular. Essas tentativas, que partiram especialmente de grupos jovens ligados ao Fusion Rock e Rock progressivo, como o grupo Los Jaivas, buscavam discutir ideias indigenistas e americanistas a partir da construção de uma identidade coletiva. Nesse sentido, conforme já citado, podemos pensar que a música enquanto uma produção (seja composta, performada, interpretada) no presente, mas que significa em vários casos camadas de temporalidades ou passados em um “devaneio" futuro (González, 2016. p. 139).

De modo geral, a participação da juventude no cenário musical latino-americano foi fundamental para seu desenvolvimento. Ao analisar os movimentos de contracultura e globalização González debate as relações entre sociedade e cultura de massas. Sobre a contracultura de massas, tema do capítulo $\mathrm{X}$, destaca-se que as relações entre vanguarda e cultura de massas não seriam unilaterais, mas sim processos de trocas entre ambos. Situados especialmente na década de 1980, os movimentos de contracultura estariam relacionados a movimentos estudantis que se utilizariam das universidades do chilenas e brasileiras, por exemplo, como espaço de desenvolvimento do movimento de questionamento. O ambiente universitário seria adotado enquanto espaço "seguro" para discussões e embates políticos em contextos de cercamento político ainda fruto das ditaduras, em especial no Chile. Tais espaços possibilitaram a expansão da canção política, questão também trabalhada por Alfonso Padilha (2016). Para Padilha, no caso Chileno a canção política se desenvolvia em espaços inesperados e muitas vezes sob a mira do próprio governo militar, como no caso dos campos de concentração de “criminosos" criados em estádios de futebol.

Os dois últimos capítulos da obra realizam um balanço sobre as décadas finais do século XX. Pensando especialmente a construção sonora das noções de clássico a partir da eleição de cânones, assim como os processos de globalização na música latinoamericana a partir da consolidação da indústria cultural, o autor estuda o entrecruzamento das temporalidades e os processos de significação dos gêneros musicais. Partindo novamente das propostas pós-coloniais, o autor destaca que muitos

\section{CANPHLAC}


gêneros na América Latina passaram por processos de massificação, como no caso do folclore, ao mesmo tempo em que se observam a tendências desses ritmos de incorporar múltiplas referências, como o caso da presença da cultura medieval na música chilena das últimas décadas.

A obra de Juan Pablo González não apenas pode ser destacada como uma das mais recentes publicações no Brasil sobre história da música latino-americana, mas também como uma referência extremamente necessária aos estudiosos sobre o campo. De forma magistral o autor, que toma como foco a América Latina, em especial o Chile, Argentina e Brasil, destaca processos complexos como as ideias de juventude e gênero dialogando com pesquisadores de áreas diversas, desde a musicologia e a história até os estudos pós-coloniais e os estudos culturais. Contudo, talvez uma das principais contribuições de González sejam os apontamentos sobre as relações entre temporalidades nas canções e nos movimentos artísticos e de vanguarda. Deste modo, o autor aponta para a existência de estratos de tempo ou temporalidades, para retomar os estudos de Reinhart Koselleck (2014), que se acumulam e confluem no decorrer das trajetórias, usos e performances da canção, seus interpretes, compositores, da industria cultural, entre outros envolvidos...

\section{Referências}

HARTOG, François. Regimes de Historicidade: Presentismo e Experiências do Tempo. Belo Horizonte: Autêntica, 2013.

KOSELLECK, Reinhart. Estratos do tempo: estudos sobre a História. Rio de Janeiro: Contraponto, Ed. PUC-RJ, 2014.

PADILHA, Alfonso. La música en una cárcel de la dictadura chilena. VALENTE,

Heloísa de A. Duarte; PEREIRA, Simone Luci. Com Som, Sem Som - Liberdade políticas, liberdades poéticas. São Paulo: Letra e Voz/FAPESP, 2016.

\section{GANPHLAC}

